\title{
Genetic Divergence Studies for Bulbing and Related Traits in Garlic Germplasm during Kharif Season
}

\author{
Ashwini P. Benke*, Somnath Dukare, Vijay Mahajan and Major Singh
}

ICAR-Directorate of Onion and Garlic Research, Rajgurunagar-410505; Pune, India

*Corresponding author

\begin{tabular}{|l|}
\hline K e y w o r d s \\
Garlic, Genetic \\
diversity, kharif
\end{tabular}

A B S T R A C T

Garlic (Allium sativum) is second important allium crop grown in India after onion. It spite of exclusively propagated by vegetative method, crop shows wide variation in agromorphological traits. For developing varieties with good yield and other favourable traits use of breeding techniques in an option. But in garlic, inability of formation of seed becomes barrier for using introgression breeding techniques. This limits the genetic enhancement of crop, however clonal selection narrow down the gene pool of crop. Further garlic enjoys countywide distribution and worldwide dynamic importance. However in India its growth habit restricted to Rabi season only. ICAR-DOGR serve as National Active Germplasm Site (NAGS) for garlic, where 700 garlic germplasm being maintained, collected from different states of India. For checking agro-climatic adaptability of garlic genetic resource present experiment was laid out. Here, total 625 garlic accessions were evaluated during kharif season for nine quantitative and five qualitative traits in two replications for two years. In pooled analysis only 68 bulb forming accessions were selected for further studies. Average values of different traits were taken for secondary analysis as non-significant difference found between years to accessions interaction. Cluster analysis (Ward 1963 method) based on fourteen agro-morphological traits sorted 68 genotypes into five main groups as cluster 1 (11 accessions), cluster 2 (7 accessions), cluster 3 (3 accessions), cluster 4 (33 accessions), cluster 5 (14). Dendrogram based on hierarchal clustering grouped the genotypes based on their morphological traits, however the grouping of genotypes did not correspond with their geographic origin. Characters like marketable yield, polar diameter, equatorial diameter, average bulb weight, number of cloves per bulb and TSS were found to be major traits in distinguishing major cluster of garlic genotype at phenotypic level. Highest genetic distance was reported between accession 202 and DOGR-499 (14.44), however accession 695 and 14 found to be most similar with minimum genetic distance i.e. 0.95. Principal component analysis revealed that first five component contribute to maximum $95 \%$ of variability. This study is first report that covers characterization and adaptation of garlic genotypes during kharif season.

\section{Introduction}

Garlic (Allium sativum L.) is a diploid $(2 \mathrm{n}=$ 16) bulbous crop grown worldwide for culinary and medicinal purpose. Its native home and existence as a truly wild species, is not yet cleared and pretend to be originated at Central Asia as discussed by Hong and Etoh, 
1996. According to Vavilov (1951), Allium longicuspis $\mathrm{Rgl}$ is an endemic species of central Asia and wild ancestor of garlic.

Garlic bulbs are rich sources of carbohydrates, proteins, phenols and antioxidants. Besides this garlic also constitute some other chemicals as additional protection for those insects and animals not deterred by its volatile metabolites sulphur based compound, (+) Sallyl-1 cysteine sulfoxide oralliine. The garlic has been utilized since the very beginnings of Ayurveda, the traditional medical system of India, as an anti-inflammatory, analgesic, antipyretic, sedative, antioxidant, and antiepileptic agent. It acts as curative measure upon cardiac diseases and cancer.

The latest global review of area and production shows that among major vegetables, garlic ranks fifth in area and seventh in production. However in India, natural stand of garlic is found in northern part of country where relatively cool winter and hot and dry summer occurs. Garlic is grown in the northern parts especially in Gujarat, Haryana, Punjab, Madhya Pradesh and Maharashtra, and in a few southern localities, especially the cold hilly tracts of Ooty and Kodai kanal, Tamil Nadu. A total of 1,264 MT garlic is been produced in year 2010-11. Gujarat is the largest producer of garlic in India with production of $275 \mathrm{MT}$, followed by Madhya Pradesh (228MT production) (Gupta, 2011). Until recently, characterization of garlic germplasm on the basis of morphological traits accomplished worldwide by Bradley et al., 1996, Garcia et al., 2003, Pathee et al., 2006, Buso et al., 2008, Asili et al., 2010, Khar 2012, Singh et al., 2014 etc. In India although crop enjoys worldwide distribution and dynamic importance, its growth habit are restricted to rabi season only. Further as major available garlic used as seed material in that particular season, there is glut in market leads to price hike. More above short day garlic completes its life cycle with in five months so there is alternative to grow the crop twice in year. Hence present experiment planned to check and identify kharif season suitable garlic ecotypes among available genetic resources at ICAR-DOGR. In future identified acclimatized genotypes can be purified by clonal selection method for promising trait like high yield, early maturity and bolting free.

\section{Material and method}

Present study has been carried out at ICARDOGR farm, Rajgurunagar which located at elevation: $645 \mathrm{~m}$ coordinates: $18.8550^{\circ} \mathrm{N}$, $73.8875^{\circ}$ E, Pune. Total 400 garlic accessions collected from different agro-climatic regions of India (Table 1) has been planted in Latin square design in two replicates during kharif 2015 and 2016. In both years out of 400 evaluated accessions, only 66 accessions could able to develop proper bulb however in remaining accessions bulb induction was observed but no longer proper bulb enlargement with lateral bud differentiation. Bulb forming accessions along with its origin/collected state is mentioned in table 1 .

Using 66 bulbing accessions, nine quantitative and six qualitative traits were recorded as per DUS guidelines over five representative samples in each replication. Further this replicated data used for analysis of variance using SAS9.3 software in both years. In pooled analysis, as no significant difference was found between years into accession interaction, mean data of both years used for further secondary analysis which includes grouping of genotypes using agro morphological traits, correlation studies among traits, and principal component analysis. Average data was subjected to JMP pro software for clustering analysis and PCA calculations.

Results and Discussion 
In case of garlic, a clonal propagated crop knowledge of genetic diversity helps in direct selection of promising genotype and to develop variety. In present experiment after field evaluation of 400 garlic accessions only 66 accessions could able to form bulbing. In rest of accessions only vigorous vegetative growth but no bulb induction observed. This may happened as garlic crop is highly photo and temperature sensitive crop. Initial 50 days after planting crop needs 1) Night temperature between 10 to $15 \mathrm{C} 2$ ) Day temperature between 25 to $28 \mathrm{C} \mathrm{3)} 70$ to $80 \%$ humidity in air 4) 11 to 12 hours photoperiod. However in next 30 to 40 days when bulb enlargement and clove differentiation starts crops require lower night temperature and higher day temperature with less humidity compare to previous 50 days.

As kharif crop generally planted on $15^{\text {th }}$ June up to $15^{\text {th }} \mathrm{July}$, initial crop growth stages gets simulated environmental conditions alike rabi season. But after 50 days of planting, at the critical bulb induction stage humidity get increased and sunshine hours reduced due to uneven rainy days and cloudy climate. The genotypes having inherent capability to cope up with such challenging climatic situations are survived and found promising for kharif season. Further there is need to screen the diverse population for bulbing in kharif at molecular level to identify related QTL. Molecular level study will help to understand the phenomenon more critically.

In bulbing genotypes, nine morphological traits has been recorded (Table 2) with sufficient variation. Accession number 266,493 and 784 recorded highest yield i.e.5.5 to $5.9 \mathrm{q} / \mathrm{ha}$. In case of bulb size, average bulb weight was 5.81 but promising lines had bulb with more than $10 \mathrm{gm}$ bulb weight with ovate size bulb shape. Garlic genotype 499, 553, 50 and 24 are identified as high TSS lines (45.2 to 46.6 degree brix). Highest variance noted in weight of 50 cloves (146.08) as within entire population there is wide divergence in shape and size of bulbs as indicated in polar diameter and equatorial diameter. Among recorded qualitative traits wide variation noted as described in table 3 .

\section{Diversity studies}

Cluster analysis based on morphological traits is an older breeding tool to get understand genetic resource for selecting genotypes for large scale multiplication and planning crop improvement programme. In cluster analysis, total 66 garlic accessions were primarily grouped into five main clusters based on genetic distance calculated upon fifteen agro morphological traits (Fig. 1). In grouping pattern there was no correlation observed among geographical origin of the accessions and clustering pattern as accessions from same state were clustered into different groups and accessions originated from different states clubbed in one cluster.

Maximum genetic distance (14.44) was recorded between accession 202 and DOGR 499 while minimum genetic distance found in 695 and 14 (0.95). Some similar research could also be referenced. This grouping will helpful to breeder to select trait specific genotypes for further selection and development of variety. Here, cluster number III consists of all high yielding accessions hence contributing traits average bulb weight, polar diameter and equatorial diameter also record highest values (Table 4)

However, cluster I contain accessions with highest weight of 50 cloves. As primarily shown in table, highest TSS recorded by cluster 3, highest TSS lines are present in cluster IV which suggest need to refine grouping on more critical level. 
Table.1 Origin/state wise distribution frequency of garlic accessions

\begin{tabular}{|c|c|c|c|}
\hline Sr. No & Origin state & $\begin{array}{l}\text { Total no. of } \\
\text { accessions }\end{array}$ & Code name of accessions \\
\hline 1 & Andhra Pradesh & 2 & $367 \& 543$ \\
\hline 2 & Arunachal Pradesh & 1 & 698 \\
\hline 3 & Assam & 1 & 695 \\
\hline 4 & Bihar & 1 & 730 \\
\hline 5 & Gujarat & 15 & $\begin{array}{l}1,3,9,14,148,202,279,282,324,347,414,460,489,540 \& \\
\text { DOGR-744 }\end{array}$ \\
\hline 6 & Haryana & 4 & $51,214,689 \& 756$ \\
\hline 7 & Jammu \&Kashmir & 1 & 439 \\
\hline 8 & Madhya Pradesh & 6 & $278,303,621,753,755 \& 784$ \\
\hline 9 & Maharashtra & 7 & $50,201,266,329,425,493 \& 759$ \\
\hline 10 & New Delhi & 8 & $244,257,357,438,443,502,553 \& 595$ \\
\hline 11 & Odisha & 8 & $364,432,441,709,710,712,742 \& 742$ \\
\hline 12 & Punjab & 1 & 517 \\
\hline 13 & Rajasthan & 2 & $534 \& 746$ \\
\hline 14 & Sikkim & 3 & $665,668 \& 671$ \\
\hline 15 & Uttarakhand & 6 & $24,187,437,593$, DOGR-243 \& DOGR-499 \\
\hline
\end{tabular}

Table. 2 Trait potential of evaluated genotypes with respect to mean, range,

Std. dev. and variance

\begin{tabular}{|c|l|c|c|c|c|c|}
\hline \multirow{2}{*}{ Sr. No. } & \multicolumn{1}{|c|}{ Trait } & Mean & \multicolumn{2}{c|}{ Range } & Std. Dev. & Variance \\
& & & Min & Max & & \\
\hline $\mathbf{1}$ & Wt. With Leaves(Kg) & 0.20 & 0.10 & 0.48 & 0.08 & 0.01 \\
\hline $\mathbf{2}$ & Wt. Without leaves(Kg) & 0.17 & 0.09 & 0.41 & 0.07 & 0.01 \\
\hline $\mathbf{3}$ & yield q/ha & 3.36 & 0.81 & 5.92 & 0.69 & 0.48 \\
\hline $\mathbf{4}$ & PD(mm) & 20.78 & 17.77 & 24.28 & 1.52 & 2.32 \\
\hline $\mathbf{5}$ & ED(mm) & 20.96 & 17.02 & 30.21 & 2.98 & 8.89 \\
\hline $\mathbf{6}$ & ABW & 5.81 & 3.48 & 12.08 & 1.52 & 2.33 \\
\hline $\mathbf{7}$ & NC/B & 7.84 & 4.40 & 15.00 & 2.44 & 5.96 \\
\hline $\mathbf{8}$ & W50C & 39.65 & 16.97 & 70.35 & 12.09 & 146.08 \\
\hline $\mathbf{9}$ & TSS & 42.23 & 35.92 & 46.64 & 2.41 & 5.80 \\
\hline
\end{tabular}

(PD- Polar diameter; ED- Equatorial diameter; ABW- Average Bulb Weight; NC/B- Number of Cloves per Bulb;W50C- Weight of 50 Cloves; TSS- Total Soluble Solids))

Table.3 Distribution frequency of qualitative traits among 66 genotypes

\begin{tabular}{|l|l|l|}
\hline Sr. no. & Trait name & Class wise distribution among genotypes \\
\hline 1 & Shape of Bulb & Transverse Elliptic- 26; Ovate- 27; Circular-13 \\
\hline 2 & Colour of Bulb & White- 40; Purple-26 \\
\hline 3 & Colour of Clove & White-38; Purple-28 \\
\hline 4 & Bulb Compactness Of Clove & Loose-14; Medium-32; Compact-20 \\
\hline 5 & Clove -Colour Of Flesh & White- 33; Yellowish-33 \\
\hline 6 & Bulb Distribution of Clove & Radial-24; Non-radial-42 \\
\hline 7 & Bulb Shape Of Base & Recessed-16; Flat-33; Rounded-20 \\
\hline
\end{tabular}


Table.4 Cluster-wise mean performance of yield and contributing traits

\begin{tabular}{|l|c|c|c|c|c|c|c|c|}
\hline Traits & $\begin{array}{c}\text { Total No of } \\
\text { Accessions }\end{array}$ & $\begin{array}{c}\text { MY } \\
\text { q/ha }\end{array}$ & $\begin{array}{c}\text { PD } \\
(\mathbf{m m})\end{array}$ & $\begin{array}{c}\text { ED } \\
(\mathbf{m m})\end{array}$ & ABW & NC/B & W50C & TSS \\
\hline Cluster I & 11 & 2.23 & 21.71 & 23.49 & 6.86 & 6.78 & 52.60 & 41.92 \\
\hline Cluster II & 7 & 2.21 & 20.98 & 22.74 & 6.71 & 11.86 & 24.54 & 42.22 \\
\hline Cluster III & 3 & 3.83 & 23.48 & 29.26 & 8.91 & 13.53 & 32.03 & 43.16 \\
\hline Cluster IV & 33 & 1.34 & 21.02 & 20.12 & 5.63 & 7.10 & 42.28 & 42.52 \\
\hline Cluster V & 14 & 1.11 & 18.81 & 18.29 & 4.30 & 7.20 & 32.46 & 41.61 \\
\hline
\end{tabular}

(MY- Marketable yield; PD- Polar diameter; ED- Equatorial diameter; ABW- Average Bulb Weight; NC/BNumber of Cloves per Bulb; W50C- Weight of 50 Cloves; TSS- Total Soluble Solids)

Fig.1 Dendrogram showing genetic distance among kharif garlic accessions plotted on basis of sixteen traits

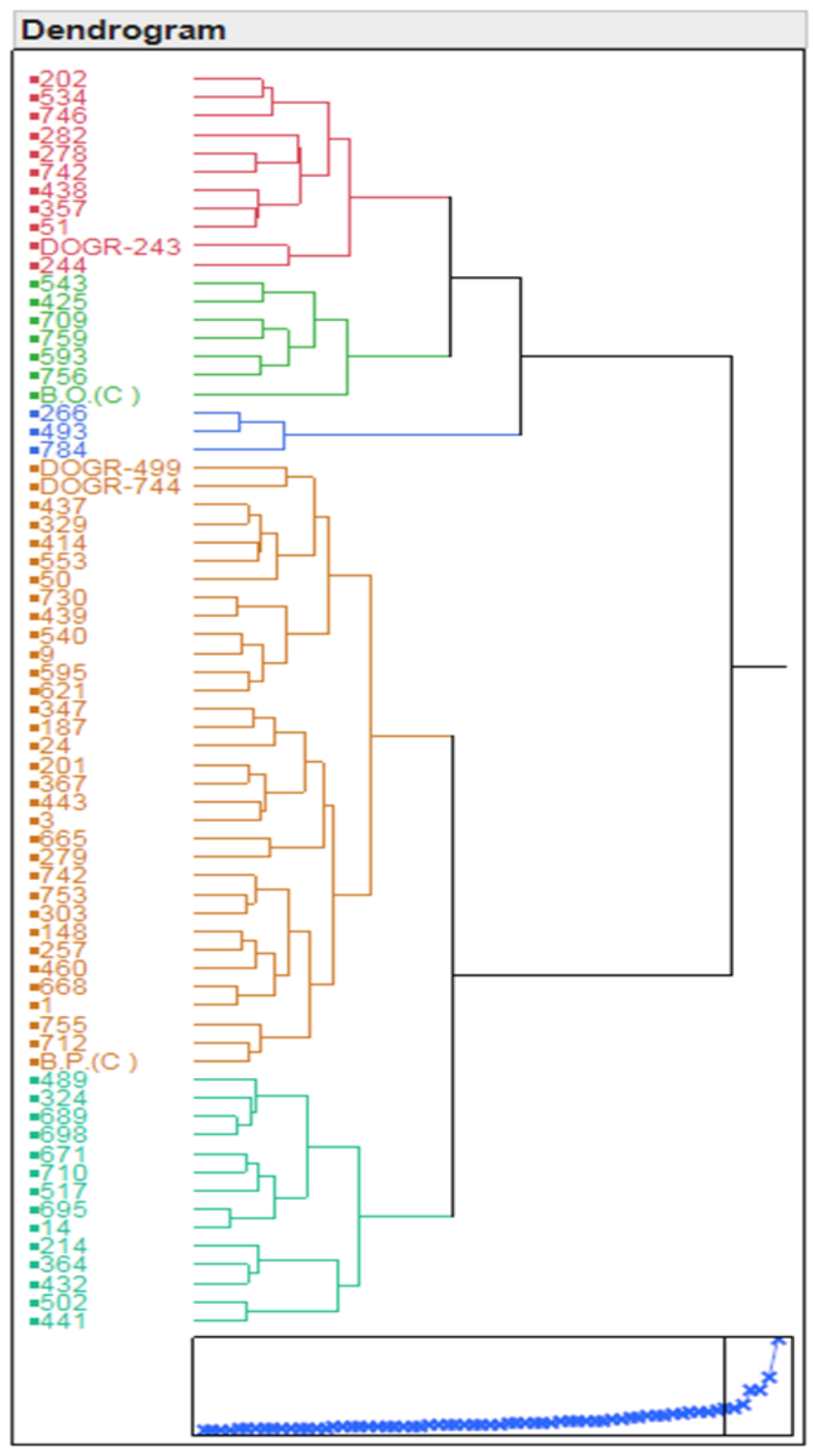


Fig.2 Score plot loading with associated traits for first three components

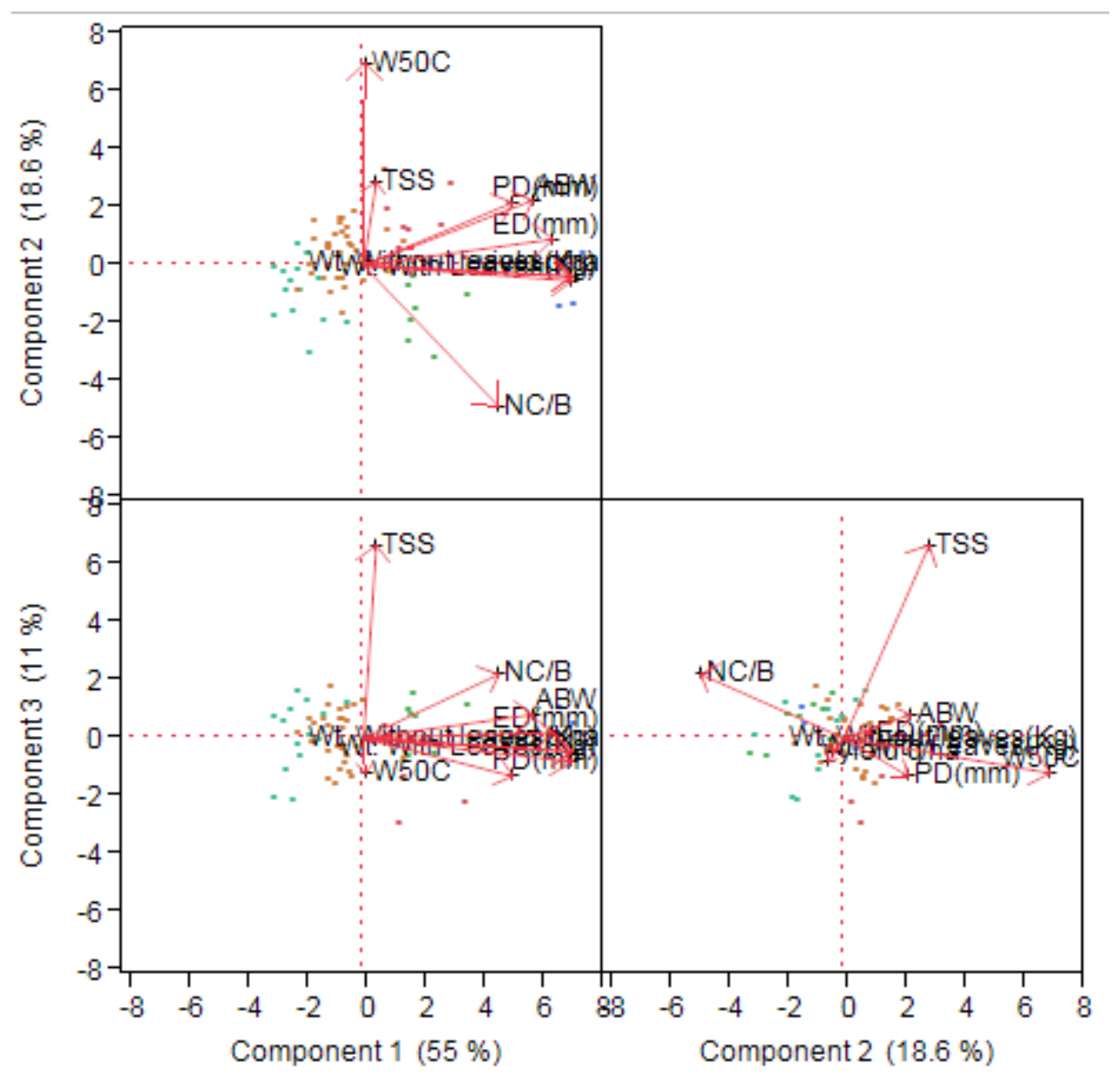

Principal coordinate analysis based on traits relative with yield clustered 66 genotypes into three groups (Fig. 2). First three components were accounts for $80 \%$ of total variation. Major traits such as total yield, average bulb weight, polar diameter and equatorial diameter played important role in contributing $55 \%$ variation due to first component with 4.94 eigenvalue however weight of 50 cloves and total soluble solids leads to variation in component second and third with 1.67 and 0.98 eigenvalues respectively. As explained by PCA researcher interested in high yield can concentrate on group first however for getting high TSS lines they have to exploit group three. For both mentioned traits identified genotypes need improvement through clonal selection purification and stability.
Garlic is a clonal propagated crop known for its medicinal and condimental properties. Till date variability in this crop published by countries like China, Brazil, Nepal, Australia, Argentina and USA at agro-morphological, biochemical and Molecular level (Pathee et al., 2006, Garcia et al., 2003, Buso et al., 2008, Bradley et al., 1996, Asili et al., 2010). However in India also different researchers worked on few genotypes along with some varieties of garlic (Singh et al., 2014; Khar. A 2012; Khar et al., 2008). But this paper is a first report of screening India's almost all tropical region representative genotypes for kharif season suitability. Although not all genotypes able to form bulb a group of bulbing accessions identified and evaluated for phenotypic traits. Suffice variability in qualitative as well as quantitative traits has 
been revealed in two years experiment for yield and other related parameters. In genotypic performance high yielding ecotypes identified, same way through divergence study such genotypes were sorted. Wang et al., (2014) reported that three Chinese accession yielded more than 15t/ha while Panthee et al., (2006) recorded highest yield as $61 \mathrm{t} / \mathrm{ha}$. Besides quantitative traits, qualitative traits too display good amount of variation. CA revealed same results alike clustering where yield and other contributing characters played major role for divergence. Here similar results were observed by Panthee et al., (2006).

Clustering of germplasm based on scored traits is easiest method to identify genetically distant trait specific genotypes. This method has been very popular in cereals like rice, wheat and so on. In garlic also in China 212 accessions sorted into six groups on the basis of morphological traits by Wang et al., (2014), similarly Panthee et al., (2006) revealed three groups from evaluating 179 garlic accessions from Nepal. Menezes Sobrinho et al., (1999) conducted a study to 89 garlic germplasm of Brazil and found 13 clusters. Lallem and et al., (1994) also evaluated 65 garlic accessions and found six clusters on the basis of morphological traits. In present experiment, we have clustered 66 genotypes in five groups where cluster number three defines high yield potential genotypes but for specifying other traits like TSS there is need to sort population more closely. As group III shows highest mean for TSS, genotype DOGR-499 from group IV recorded highest TSS among entire population i.e., 46 degree brix..

Evaluation of garlic genotypes during off season (kharif) will definitely lead to open door for alternate cultivation season of crop. This experiment able to screen and identify the promising accessions for yield and related traits. Further improvement in traits will give a garlic variety for kharif season. This ultimately enhances production of garlic in India. Rather helpful to manage the price hike when no garlic was chiefly available for consumption to normal community.

\section{Acknowledgement}

Authors thanks to all skilled personals who helped to record the data and special thanks to Dr. Jai Gopal for encouragement and support to initiate the garlic field trial during off season.

\section{References}

Asili, A.; Behravan, J.; Naghavi, M. R.; Asili, J 2010. Genetic diversity of Persian shallot (Allium hirtifolium) ecotypes based on morphological traits, allicin content and RAPD markers. J. Med. Aromat. Plants. Vol.1 No.1.1-6.

Bradley K, Rieger MA, Collins G 1996. Classification of Australian garlic cultivars by DNA finger printing. Anim. Prod. Sci. 36(5): 613-618.

Buso, G.S.C., Paiva, M.R., Torres, A.C., Resend, F.V., Ferreira, M.A., Buso, J.A., Dusi, A.N., 2008. Genetic diversity studies of Brazilian garlic germplasm and quality control of garlicclover production. Genet. Mol. Res. 7(2): 534-541.

Garcia Lampasona1 S., Mart'inez L. and Burba J.L. 2003. Genetic diversity among selected Argentinean garlic clones (Allium sativum L.) using AFLP (Amplified Fragment Length Polymorphism) Euphytica 132: 115119.

Gupta, R.P 2011. National Horticultural Research and Development Foundation (NHRDF) Research 1978-2010, pg 53.

Hong, C.J. and T. Etoh, 1996. Fertile clones of garlic (Allium sativum L.) abundant 
around the Tien Shan Mountains. Breed. Sci. 46:349-353.

Khar A. 2012. Alliaceae Cross amplification of onion derived microsatellites and mining of garlic EST database for assessment of genetic diversity in garlic. Proc. $6^{\text {th }}$ IS on Edible. Acta Hort. 969, ISHS.

Khar A. Asha Devi A. Lawande K.E. 2008. Analysis of genetic diversity among Indian garlic cultivar and breeding lines using RAPD markers. Indian J. Genet., 68(1): 52-57.

Lallemand J, Messian C, Briand F, Etoh T 1994. Delimitation of varietal groups in garlic (Allium sativum L.) by morphological, physiological and biochemical characters. In: I international symposium on edible alliaceae. vol 433, pp 123-132.

Menezes-Sobrinho J.A., de Charchar J.M., Aragao F.A.S. and Menezes-Sobrinho J.A. de 1999. Morphological characterization of garlic germplasm by multivariate analyses of principal components and canonic variables. Horticultura Brasileira 17: 96-101.

Panthee DR, Kc RB, Regmi HN, Subedi PP, Bhattarai S, Dhakal J 2006. Diversity analysis of garlic (Allium sativum L.) germplasms available in Nepal based on morphological characters. Genet Resour Crop Evol 53(1):205-212. Doi: 10.1007/s10722-004-6690-z.

Singh L. Koul G. and Gohil R. 2014. Analysis of morphological variability in the Indian germplasm of Allium sativum L.Plant Systematics. Evo. 300: 245-254.

Vavilov N.I. 1951. The origin, variation, immunity and breeding of cultivated plants. Soil Sci., 72(6):482.

Wang H., Li. X., Shen. Di, Oiu Y., Song J. 2014. Diversity evaluation of morphological traits and allicin content in garlic (Allium sativum L.) from China. Euphytica. 198: 243-254.

\section{How to cite this article:}

Ashwini P. Benke, Somnath Dukare, Vijay Mahajan and Major Singh. 2018. Genetic Divergence Studies for Bulbing and Related Traits in Garlic Germplasm during Kharif Season. Int.J.Curr.Microbiol.App.Sci. 7(01): 2920-2927. doi: https://doi.org/10.20546/ijcmas.2018.701.349 